\title{
Hepatitis C co-infection is associated with an increased risk of incident chronic kidney disease in HIV-infected patients initiating combination antiretroviral therapy
}

Carmine Rossi ${ }^{1}$, Janet Raboud ${ }^{2,3}$, Sharon Walmsley ${ }^{3}$, Curtis Cooper ${ }^{4}$, Tony Antoniou ${ }^{5}$, Ann N. Burchell ${ }^{5}$, Mark Hull ${ }^{6,7}$, Jason Chia ${ }^{6}$, Robert S. Hogg ${ }^{6,8}$, Erica E.M. Moodie ${ }^{9}$, Marina B. Klein ${ }^{1,10^{*}}$ and the Canadian Observational Cohort (CANOC) Collaboration

\begin{abstract}
Background: Combination antiretroviral therapy (CART) has reduced mortality from AIDS-related illnesses and chronic comorbidities have become prevalent among HIV-infected patients. We examined the association between hepatitis $\mathrm{C}$ virus (HCV) co-infection and chronic kidney disease (CKD) among patients initiating modern antiretroviral therapy.

Methods: Data were obtained from the Canadian HIV Observational Cohort for individuals initiating CART from 2000 to 2012. Incident CKD was defined as two consecutive serum creatinine-based estimated glomerular filtration (eGFR) measurements $<60 \mathrm{~mL} / \mathrm{min} / 1.73 \mathrm{~m}^{2}$ obtained $\geq 3$ months apart. CKD incidence rates after cART initiation were compared between HCV co-infected and HIV mono-infected patients. Hazard ratios (HRs) and 95\% confidence intervals $(\mathrm{Cls})$ were estimated using multivariable Cox regression.
\end{abstract}

Results: We included 2595 HIV-infected patients with eGFR $>60 \mathrm{~mL} / \mathrm{min} / 1.73 \mathrm{~m}^{2}$ at CART initiation, of which $19 \%$ were HCV co-infected. One hundred and fifty patients developed CKD during 10,903 person-years of follow-up (PYFU). The CKD incidence rate was higher among co-infected than HIV mono-infected patients (26.0 per 1000 PYFU vs. 10.7 per 1000 PYFU). After adjusting for demographics, virologic parameters and traditional CKD risk factors, HCV co-infection was associated with a significantly shorter time to incident CKD (HR 1.97; 95\% Cl: 1.33, 2.90). Additional factors associated with incident CKD were female sex, increasing age after 40 years, lower baseline eGFR below $100 \mathrm{~mL} / \mathrm{min} / 1.73 \mathrm{~m}^{2}$, increasing HIV viral load and cumulative exposure to tenofovir and lopinavir.

Conclusions: HCV co-infection was associated with an increased risk of incident CKD among HIV-infected patients initiating CART. HCV-HIV co-infected patients should be monitored for kidney disease and may benefit from available HCV treatments.

Keywords: Antiretroviral therapy, Chronic kidney disease, Co-infection, Glomerular filtration, Hepatitis C, HIV

\footnotetext{
* Correspondence: marina.klein@mcgill.ca

${ }^{1}$ Research Institute of the McGill University Health Centre, Montréal, Canada

${ }^{10}$ Division of Infectious Diseases and Chronic Viral Illness Service, McGill

University Health Centre, 1001 Decarie Boulevard, D02.4110, Montréal H4A

3J1, Canada

Full list of author information is available at the end of the article
} 


\section{Background}

Combination antiretroviral therapy (cART) has been associated with both a substantial reduction in AIDS and greater life expectancies in both low and high-income HIV settings [1-3]. With increasing life expectancies, morbidity and mortality from non-AIDS and ageingrelated co-morbidities account for a larger proportion of the HIV disease burden [4]. Co-infection with chronic hepatitis $\mathrm{C}$ virus $(\mathrm{HCV})$ is common among HIV-infected patients and is associated with many of the extrahepatic, non-AIDS and ageing-related co-morbidities observed in this population [5]. These co-morbidities include cardiovascular, metabolic, renal, and neurological illnesses, which have been attributed to chronic HCV infection in both the general and HIV-infected populations [6-8]. Indeed, the diagnoses of these extrahepatic illnesses have increased among hospitalized patients with $\mathrm{HCV}$ and account for a greater proportion of health service utilization among co-infected individuals $[9,10]$.

Chronic kidney disease (CKD) is an important comorbidity in HIV-infected persons [11]. If left unmanaged, HIV-infected patients with CKD are at greater risk of serious cardiovascular complications and premature mortality [12-14]. The etiology of CKD in HIV-infected patients is complex and has been related to both traditional, non-viral kidney impairment risk factors, such as hypertension, diabetes, dyslipidemia, and the use of nonsteroidal anti-inflammatory drugs (NSAIDs), whose prevalence have all increased in the modern cART era, as well as emerging HIV-related risk factors, such as long-term use of potentially nephrotoxic antiviral agents, incomplete immune recovery, and ongoing substance abuse [15-17]. Chronic HCV has been both directly and indirectly implicated in the development of CKD. Directly, HCV has been associated with the development of glomerulonephritis, via increased autoantibody IgM production with rheumatoid factor activity, leading to mixed cryoglobulinemia and deposition into glomerular capillary and tubules $[18,19]$. Indirectly, HCV has been associated with an increased risk of insulin resistance and atherosclerosis, which are important CKD risk factors [20].

Given the complex interplay between viral and nonviral risk factors, the impact that chronic $\mathrm{HCV}$ may have on CKD in the modern cART era is unclear. A metaanalysis of 27 studies in HIV-infected individuals enrolled between 1989 and 2006 showed that HCV infection was associated with an increased risk of CKD. However, there was both statistical heterogeneity and variation in measured outcomes (i.e. CKD measured by proteinuria, hospitalization, incidence of HIV-associated nephropathy (HIVAN), or increased creatinine concentration), as well as no adjustment for confounding [21]. Studies included a combination of treatment-naïve and experienced patients, including treatment with indinavir, and therefore may no longer be representative of the HIV-infected population currently in clinical care. The objective of this study was to determine if $\mathrm{HCV}$ coinfection is associated with an increased risk of incident CKD in a cohort of HIV-infected Canadians initiating modern antiretroviral therapy.

\section{Methods}

\section{Study population}

Data were analyzed from the Canadian Observational Cohort (CANOC) [22]. This retrospective HIV cohort study is a collaboration of eight separate population and clinic-based cohorts from Canada's largest provinces. Briefly, treatment-naive HIV-infected patients who have initiated cART since January 1st, 2000, are eligible for inclusion. The cohort is broadly representative of the HIV population accessing treatment and comprises approximately half of all individuals who have initiated cART in Canada since 2000 [22]. Every second year, each participating cohort electronically submits a pre-defined series of demographic, clinical, and HIV treatment variables for their patients to the Data Coordinating Site at the British Columbia Centre for Excellence in HIV/AIDS Research. As of December 31st, 2012, 8980 cART initiators have been included in CANOC. All participating cohorts have received approval from their institutional ethics boards to contribute anonymous patient data to CANOC.

\section{Study design and inclusion criteria}

A longitudinal cohort design was employed to examine the association between $\mathrm{HCV}$ co-infection and incident CKD. We defined baseline as the date of CART initiation and we included all individuals who (1) had at least one serum creatinine ( $\mathrm{SCr}$ ) measurement within 30 days prior to starting cART or up to 7 days after, (2) had at least two follow-up SCr measurements, at least 90 days apart, and (3) did not have a baseline estimated glomerular filtration rate (eGFR) measurement $<60 \mathrm{~mL} / \mathrm{min} /$ $1.73 \mathrm{~m}^{2}$ (see below).

\section{Chronic kidney disease}

We calculated eGFR using the 2009 SCr-based CKD-EPI equation [23]. This equation has been validated in HIVinfected populations [24]. Confirmed incident CKD was defined as two consecutive eGFR measurements $<60 \mathrm{~mL} / \mathrm{min} / 1.73 \mathrm{~m}^{2}$, obtained at least 90 days apart. The CKD event date was on the second of the two required eGFR measurements.

\section{Study covariates}

HCV exposure was ascertained by a positive HCV antibody test, qualitative or quantitative HCV RNA analysis, 
or physician reporting. HCV exposure was considered time-fixed irrespective of when the diagnosis or testing results were reported, as HCV infection precedes cART initiation in the vast majority of HIV-infected Canadians [25]. African/Caribbean ethnicity and injection drug use (IDU) as an HIV risk factor were obtained by patient self-report at baseline from patients in the Ontario HIV Treatment Network Cohort Study, from enrolment forms into the Drug Treatment Program in British Columbia, or from review of medical charts for other cohorts. Diabetes was defined by either clinical diagnoses or random serum glucose $\geq 11.1 \mathrm{mmol} / \mathrm{L}$. Hypertension was also defined by either clinical diagnoses or systolic blood pressure $\geq 140 \mathrm{mmHg}$ or diastolic blood pressure $\geq 90 \mathrm{mmHg}$ [26]. Liver fibrosis was measured using the aspartate aminotransferase-to-platelet ratio index (APRI) and values $\geq 1.5$ were indicative of moderate fibrosis [27]. AIDS-defining events were defined based on the 1993 Centers for Disease Control and Prevention classification [28].

\section{Statistical analyses}

Eligible patients were followed from baseline (i.e. cART initiation) until the earliest of (1) incident CKD, (2) death, (3) loss-to-follow-up, or (4) study end date of December 31st, 2012. Person-time for individuals without CKD was censored at the date of the last eGFR measurement or date of death. Cumulative incidence curves were created to explore the association between $\mathrm{HCV}$ and CKD-free survival [29]. Univariable and multivariable Cox proportional hazards $(\mathrm{PH})$ models were fit to examine the association between HCV co-infection and CKD. The multivariable model was adjusted for baseline age, sex, African/Caribbean ethnicity, eGFR, and year of cART initiation and time-updated measurements of $\mathrm{CD} 4^{+}$cell count, HIV viral load, liver fibrosis, and tenofovir, atazanavir, and lopinavir use. A second model additionally adjusted for time-updated diabetes and hypertension. Covariates were selected a priori based on their plausibility as confounders. As there was evidence of non-linearity between age and baseline eGFR with CKD, we modeled these covariates with linear splines with a single age knot at 40 years and a single baseline eGFR knot at $100 \mathrm{~mL} / \mathrm{min} / 1.73 \mathrm{~m}^{2}$ [30]. Chronic comorbid conditions of liver fibrosis, diabetes and hypertension were modeled as cumulative binary exposures and the antiretroviral agents were modeled as cumulative use. We explored interaction between HCV co-infection and IDU as an HIV risk factor, as previous research has shown poorer clinical outcomes for this group [31]. Missing covariate data for HCV co-infection, African/ Caribbean ethnicity, liver fibrosis, diabetes and hypertension was handled using fully conditional specification multiple imputation (MI) [32]. The imputation model included all covariates in the multivariable model, an indicator for CKD, and a measure of the cumulative baseline hazard using the Nelson-Aalen estimator [33]. We created 10 imputed data sets and combined regression results using Rubin's rules [32].

We also performed several sensitivity analyses. First, given there were a large proportion of patients without a baseline eGFR that were excluded from the analysis, we used inverse-probability weighting to account for the fact that certain patients were under-represented in our analytical cohort [34]. Second, because there is a strong relationship between increasing age and declining kidney function, we considered using age as the time scale in the primary Cox PH model. Third, we considered reclassifying exposed co-infected person-time based on the date of first positive HCV serologic or molecular test, rather than assume patients were initially co-infected [35]. Lastly, given the large number of missing data on hypertension, we examined the sensitivity of the missing at random MI assumption [36]. STATA version 13.1 (College Station, TX) and SAS version 9.4 (Cary, NC) were used for the analyses.

\section{Results}

Of the 8980 patients who initiated cART between January 1st, 2000, and December 31st, 2012, 2595 (29\%) were eligible for inclusion into our study (Fig. 1). Most patients were excluded (64\%) because they did not have a baseline SCr measurement. Excluded individuals were more likely to be female, white, HCV co-infected, report IDU as an HIV risk factor, and used tenofovir-based initial cART regimen (see Additional file 1: Table S1).

Baseline patient characteristics, overall and stratified by HCV co-infection, are presented in Table 1 . Most of the study patients were male $(85 \%)$ and the median age

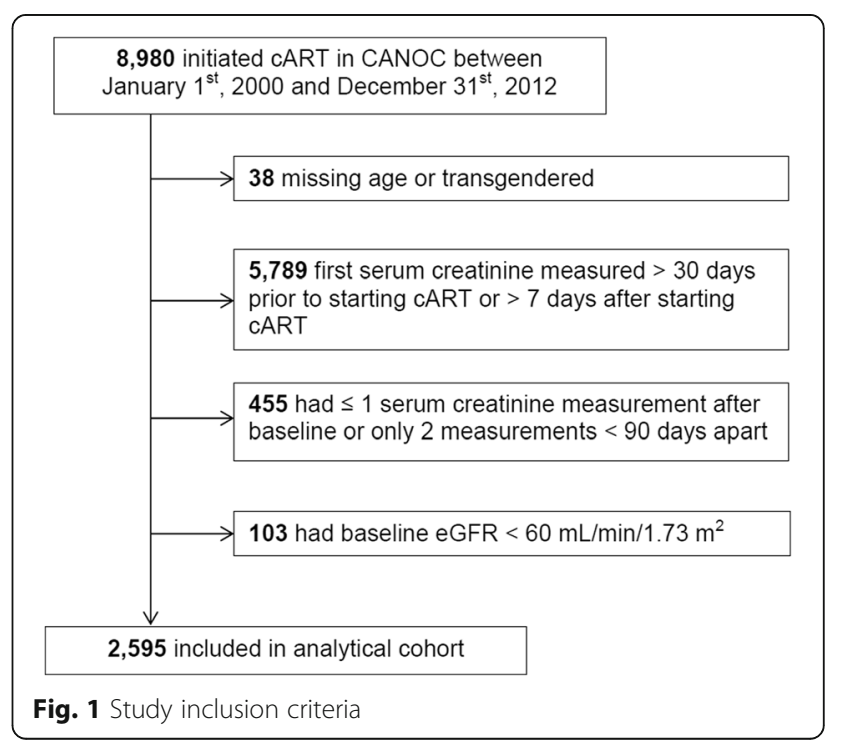


Table 1 Baseline study characteristics, overall and stratified by hepatitis C virus co-infection

\begin{tabular}{|c|c|c|c|c|}
\hline & Overall $(n=2595)$ & HCV positive $(n=484)$ & HCV negative $(n=1978)$ & Unknown $(n=133)$ \\
\hline Median age (IQR), years & $40(33,46)$ & $41(35,47)$ & $39(33,46)$ & $41(36,49)$ \\
\hline Male sex & $2195(85 \%)$ & $394(81 \%)$ & $1690(85 \%)$ & $111(83 \%)$ \\
\hline African/Caribbean ethnicity ${ }^{a}$ & $368(24 \%)$ & $17(5 \%)$ & $344(29 \%)$ & 17 (27\%) \\
\hline Median eGFR (IQR), mL/min/1.73 m² & $105(92,116)$ & $103(91,114)$ & $105(92,117)$ & $106(96,115)$ \\
\hline Injection drug use as HIV risk factor ${ }^{\text {b }}$ & $389(18 \%)$ & $302(69 \%)$ & $83(5 \%)$ & $4(4 \%)$ \\
\hline Median $\mathrm{CD}^{+}$cell count (IQR), cells/ $\mu \mathrm{L}$ & $210(102,318)$ & $190(80,290)$ & $220(110,323)$ & $200(100,319)$ \\
\hline Median HIV viral load (IQR), $\log _{10}$ copies/mL & $4.9(4.4,5.2)$ & $4.9(4.4,5.1)$ & $4.9(4.4,5.2)$ & $4.9(4.4,5.2)$ \\
\hline Previous AIDS-defining event ${ }^{c}$ & $450(19 \%)$ & $99(22 \%)$ & $331(19 \%)$ & $20(18 \%)$ \\
\hline Tenofovir use & $1410(54 \%)$ & $227(47 \%)$ & $1111(56 \%)$ & $72(54 \%)$ \\
\hline Atazanavir use & $666(26 \%)$ & $144(30 \%)$ & $494(25 \%)$ & $28(21 \%)$ \\
\hline Lopinavir use & $471(18 \%)$ & $99(20 \%)$ & $347(18 \%)$ & $25(19 \%)$ \\
\hline Median year of CART initiation (IQR) & 2007 (2004, 2009) & $2006(2003,2009)$ & $2008(2004,2009)$ & $2008(2004,2010)$ \\
\hline Liver fibrosis (APRI $\geq 1.5)^{d}$ & $145(7 \%)$ & $69(17 \%)$ & $71(5 \%)$ & $5(6 \%)$ \\
\hline Diabetes $^{e}$ & $119(5 \%)$ & $26(6 \%)$ & $89(5 \%)$ & $4(3 \%)$ \\
\hline Hypertension $^{f}$ & $74(12 \%)$ & $13(15 \%)$ & $59(12 \%)$ & $2(8 \%)$ \\
\hline \multicolumn{5}{|l|}{ Cohort province } \\
\hline British Columbia & $1103(43 \%)$ & $307(63 \%)$ & $738(37 \%)$ & $58(44 \%)$ \\
\hline Ontario & $838(32 \%)$ & $110(23 \%)$ & $694(35 \%)$ & $34(26 \%)$ \\
\hline Québec & 654 (25\%) & 67 (14\%) & 546 (28\%) & 41 (31\%) \\
\hline
\end{tabular}

$A P R I$ aspartate aminotransferase to platelet ratio index, CART combination antiretroviral therapy, IQR interquartile range, eGFR estimated glomerular filtration rate, HCV hepatitis $C$ virus

a 1045 participants (40\%) are missing data on African/Caribbean ethnicity; 138 among HCV Positive, 838 among HCV Negative, and 69 among the Unknown

b 431 participants (17\%) are missing data on injection drug use risk factor; 44 among HCV Positive, 344 among HCV Negative, and 43 among the Unknown

c 246 participants (9\%) are missing previous AIDS event histories; 31 among HCV Positive, 197 among HCV Negative, and 18 among the Unknown

d 603 participants (23\%) are missing data on liver fibrosis; 73 among HCV Positive, 484 among HCV Negative, and 46 among the Unknown

e 142 participants (5\%) are missing data on diabetes; 13 among HCV Positive, 111 among HCV Negative, and 18 among the Unknown

f 1973 participants (76\%) are missing data on hypertension; 395 among HCV Positive, 1470 among HCV Negative, and 108 among the Unknown

was 40 years (interquartile range [IQR]: 33, 46). Among the 2595 included patients, 2462 (95\%) were screened for HCV. Of these, 484 (20\%) were co-infected, with 107 (22\%) could be confirmed as having chronic HCV with molecular HCV RNA testing. Compared to HIV monoinfected, co-infected patients were older, less likely to be male or of African/Caribbean ethnicity, more likely to have a history of IDU and have liver fibrosis, less likely to be on a tenofovir-based initial cART regimen and had lower baseline $\mathrm{CD} 4^{+}$cell counts.

Of the 2595 patients in the study, 150 (6\%) developed incident CKD over a total of 10,903 person-years of follow-up (PYFU). The overall crude incidence rate was 13.8 per 1000 PYFU (95\% confidence interval (CI): 11.7 , 16.1). The median follow-up time was 3.5 years (IQR: $1.7,6.1)$. Of the 2445 patients who were censored without developing CKD, 141 died (6\%), 576 were lost-tofollow-up (23\%), and the remaining 1728 were administratively censored (71\%).

Incidence rates for CKD stratified by demographic and clinical characteristics are presented in Table 2. Crude rates were higher in females, older age groups, nonAfrican/Caribbeans, individuals with IDU as an HIV risk factor, and those with a lower baseline eGFR. CKD incidence did not increase with calendar time. The incidence of CKD among co-infected patients was substantially higher than the rate among HIV monoinfected patients; 26.0 per 1000 PYFU (95\% CI: 20.0, 33.8) and 10.7 per 1000 PYFU (95\% CI: 8.7, 13.2), respectively. The median follow-up time was similar in both groups. The incidence rate of CKD among those with an unknown HCV status was similar to the HIV mono-infected group (11.1 per 1000 PYFU; 95\% CI: 4.6, 26.7). Figure 2 depicts the cumulative incidence function for $\mathrm{CKD}$ by $\mathrm{HCV}$ co-infection status. Among Coinfected, the five-year cumulative risk of CKD after initiating cART was $11 \%$, compared to $5 \%$ among HIV mono-infected patients.

In univariable analysis, $\mathrm{HCV}$ co-infection was significantly associated with CKD (hazard ratio (HR) 2.49; 95\% CI: $1.79,3.48)$ and remained so after adjustment (HR 1.97; 95\% CI: 1.33, 2.90). Female sex (HR 2.16; 95\% CI: 1.42, 3.28), increasing age after 40 years (HR 1.51 per 5 year increase; 95\% CI: 1.35, 1.67), increasing baseline eGFR up to $100 \mathrm{~mL} / \mathrm{min} / 1.73 \mathrm{~m}^{2}$ (HR 0.60 per $5 \mathrm{~mL} / \mathrm{min} / 1.73 \mathrm{~m}^{2}$ increase; 95\% CI: 
Table 2 Crude incidence rates of chronic kidney disease, Canadian Observational Cohort 2000-2012

\begin{tabular}{|c|c|c|c|}
\hline Characteristic & $\begin{array}{l}\text { Chronic kidney } \\
\text { Disease events }\end{array}$ & $\begin{array}{l}\text { Total } \\
\text { Person-years }\end{array}$ & $\begin{array}{l}\text { Incidence } \\
\text { rate per } 1000 \\
\text { Person-years } \\
(95 \% \mathrm{Cl})\end{array}$ \\
\hline Overall & 150 & $10,903.4$ & $13.8(11.7,16.1)$ \\
\hline \multicolumn{4}{|l|}{ Sex } \\
\hline Male & 115 & 9130.4 & $12.6(10.5,15.1)$ \\
\hline Female & 35 & 1773.0 & $19.7(14.2,27.5)$ \\
\hline \multicolumn{4}{|l|}{ Ethnicity } \\
\hline African/Caribbean & 15 & 1806.6 & $8.3(5.0,13.7)$ \\
\hline $\begin{array}{l}\text { Non-African/ } \\
\text { Caribbean }\end{array}$ & 97 & 5742.7 & $16.9(13.8,20.6)$ \\
\hline Unknown & 38 & 3354.0 & $11.3(8.2,15.6)$ \\
\hline \multicolumn{4}{|l|}{ Hepatitis C Co-Infection } \\
\hline Yes & 56 & 2156.0 & $26.0(20.0,33.8)$ \\
\hline No & 89 & 8297.3 & $10.7(8.7,13.2)$ \\
\hline Unknown & 5 & 450.2 & $11.1(4.6,26.7)$ \\
\hline \multicolumn{4}{|l|}{ HIV Risk Factor } \\
\hline Injection drug use & 45 & 1709.7 & $25.1(18.8,33.7)$ \\
\hline $\begin{array}{l}\text { Non-injection } \\
\text { drug use }\end{array}$ & 89 & 7640.4 & $11.6(9.5,14.3)$ \\
\hline Unknown & 16 & 1472.3 & $10.9(6.7,17.7)$ \\
\hline \multicolumn{4}{|c|}{ Age at CART initiation, years } \\
\hline $18-39$ & 43 & 5342.6 & $8.0(6.0,10.9)$ \\
\hline $40-49$ & 41 & 3874.6 & $10.6(7.8,14.4)$ \\
\hline $50-59$ & 40 & 1369.5 & $29.2(21.4,39.8)$ \\
\hline$\geq 60$ & 26 & 316.7 & $82.1(55.9,120.6)$ \\
\hline \multicolumn{4}{|c|}{ Baseline eGFR, $\mathrm{mL} / \mathrm{min} / 1.73 \mathrm{~m}^{2}$} \\
\hline$>110$ & 25 & 3906.9 & $6.4(4.3,9.5)$ \\
\hline$>90 \& \leq 110$ & 41 & 4405.5 & $9.3(6.9,12.6)$ \\
\hline$\leq 90$ & 84 & 2591.0 & $32.4(26.2,40.2)$ \\
\hline \multicolumn{4}{|l|}{ Year of Follow-up } \\
\hline 2000-2003 & 14 & 966.4 & $14.5(8.6,24.5)$ \\
\hline 2004-2008 & 58 & 4324.0 & $13.4(10.4,17.3)$ \\
\hline 2009-2012 & 78 & 5613.0 & $13.9(11.1,17.3)$ \\
\hline
\end{tabular}

CART combination antiretroviral therapy, Cl confidence interval, eGFR estimated glomerular filtration rate

$0.52,0.69)$, HIV viral load (HR 1.20 per $\log _{10}$ increase; 95\% CI: 1,01, 1.43) and cumulative exposure to lopinavir (HR 1.12 per additional year of use, 95\% CI: $1.02,1.22$ ) were also associated with CKD in the multivariable model (Table 3). Liver fibrosis also demonstrated a trend towards greater risk of CKD (HR 1.50; 95\% CI: $0.98,2.30$ ). In a secondary analysis, including hypertension and diabetes from the model did not appreciably change the results (HR 2.02; 95\% CI: $1.36,2.99)$, although tenofovir use was now associated with CKD (HR 1.12 per additional year of use, 95\%
CI: $1.00,1.25)$. The effect of HCV co-infection did not differ between those who had IDU as a HIV risk factor and those who did not ( $p$-value for interaction term, 0.94).

Results from all sensitivity analyses were quantitatively similar to the main findings. With an inverseprobability weighted sample to account for potential selection bias, the adjusted $\mathrm{HR}$ for $\mathrm{HCV}$ co-infection was similar (HR 2.01; 95\% CI: 1.34, 3.01; see Additional file 1: Table S2). When using age as the time scale, rather than time from cART initiation, the adjusted HR increased slightly (HR 2.14; 95\% CI: 1.44, 3.20; see Additional file 1: Table S3). When we considered person-time prior to a patient's first positive HCV antibody or molecular test to be unexposed, the adjusted effect estimate was slightly attenuated (HR 1.82; 95\% CI: 1.22, 2.73). Estimates from our additional MI scenarios, where we assumed missing data patterns for hypertension depended on unobserved data, were robust to our missing data assumptions (see Additional file 1: Table S4).

\section{Discussion}

In this analysis of HIV-infected individuals initiating cART, we found that HCV co-infection was associated with a shorter time to incident CKD using a confirmed eGFR-based definition. This finding was independent of traditional CKD risk factors, which have become more prevalent in HIV-infected patients in the modern cART era [15]. Results were consistent for all sensitivity analyses using different estimation techniques. The adjusted effect size for HCV coinfection was relatively larger than other important CKD risk factors such as hypertension, diabetes, and exposure to nephrotoxic agents, such as tenofovir, atazanavir and lopinavir/ritonavir. These findings support the current guidelines for the diagnosis and management of CKD among HIV patients, which recommend annual monitoring of kidney function among those co-infected with HCV [37]. Identification of HIV patients at greatest risk of developing CKD will help targeted implementation of preventative and therapeutic strategies to slow renal function decline and determine which patients may benefit to switching newer cART regimens with safer renal profiles [38].

This is the first study to estimate the incidence of CKD among HIV-infected patients after initiating cART, which we estimated at 14 per 1000 PYFU. Previous studies have included a combination of treatment-naïve and experienced patients $[39,40]$, failed to use a confirmatory eGFR measurement $[41,42]$, or did not perform multivariable analyses [43]. Generally, results from our study were consistent with findings from other observational HIV 




Fig. 2 Cumulative incidence of chronic kidney disease by hepatitis C co-infection

cohorts. In a follow-up of HIV patients enrolled in the Strategies for Management of Antiretroviral Therapy trial, co-infected patients were $72 \%$ more likely to develop CKD and end-stage renal disease (ESRD), relative to HIV mono-infected patients [44]. This study also found that hepatitis B virus co-infection was also strongly associated with CKD and ESRD, which we did not observe in our analysis (data not shown). An analysis of data from
EuroSIDA, which had a similar CKD incidence rate (15 per 1000 PYFU) as observed in CANOC, also demonstrated a two-fold increase in the risk of eGFR-based CKD for $\mathrm{HCV}$ co-infected patients, although there was no evidence of a dose-response relationship with increasing HCV viral load [40]. In the Women's Interagency HIV Study, HCV co-infection was associated with a decline in eGFR among women with existing CKD, suggesting our findings are not restricted to males who make up the majority of participants in observational HIV cohorts [39].

In our analyses, we identified several additional CKD risk factors such female sex, increasing age, lower eGFR at treatment initiation, increasing HIV viral load, and cumulative exposure to tenofovir and lopinavir, which have previously been identified $[45,46]$. Unlike other settings in North America, however, we did not find an association between African/Caribbean ethnicity and incident CKD [47, 48]. African/Caribbean patients in CANOC were less likely to be co-infected and started cART at a younger age (median 37 years vs. 40 years), compared to non-African/Caribbean individuals. It is likely that this reduced risk in CKD among African/Caribbean individuals observed in this study can be attributed to the use of cART which substantially reduces the risk of HIVAN, a common consequence of untreated HIV infection in this population [49].

Table 3 Crude and adjusted Cox proportional hazards models for chronic kidney disease in the Canadian Observational Cohort Collaboration $^{\text {a }}$

\begin{tabular}{|c|c|c|c|}
\hline & $\begin{array}{l}\text { Unadjusted HR } \\
(95 \% \mathrm{Cl})\end{array}$ & $\begin{array}{l}\text { Adjusted } \mathrm{HR}^{\mathrm{C}} \\
(95 \% \mathrm{CI})\end{array}$ & $\begin{array}{l}\text { Adjusted HR } \\
(95 \% \mathrm{Cl})\end{array}$ \\
\hline Hepatitis C virus co-infection & $2.49(1.79,3.48)$ & $1.97(1.33,2.90)$ & $2.02(1.36,2.99)$ \\
\hline Female sex & $1.56(1.07,2.28)$ & $2.16(1.42,3.28)$ & $2.12(1.39,3.23)$ \\
\hline Age $\leq 40$ years, per 5 year increase ${ }^{b}$ & $0.97(0.78,1.21)$ & $0.84(0.67,1.07)$ & $0.82(0.65,1.04)$ \\
\hline Age $>40$ years, per 5 year increase ${ }^{b}$ & $1.59(1.45,1.74)$ & $1.51(1.35,1.67)$ & $1.45(1.31,1.62)$ \\
\hline African/Caribbean ethnicity & $0.55(0.32,0.94)$ & $0.79(0.43,1.44)$ & $0.72(0.39,1.32)$ \\
\hline Baseline eGFR $\leq 100 \mathrm{~mL} / \mathrm{min} / 1.73 \mathrm{~m}^{2}$, per $10 \mathrm{~mL} / \mathrm{min} / 1.73 \mathrm{~m}^{2}$ increase $^{\mathrm{b}}$ & $0.56(0.49,0.65)$ & $0.60(0.52,0.69)$ & $0.61(0.52,0.70)$ \\
\hline Baseline eGFR >100 mL/min/1.73 m², per $10 \mathrm{~mL} / \mathrm{min} / 1.73 \mathrm{~m}^{2}$ increase $^{\mathrm{b}}$ & $0.86(0.70,1.06)$ & $1.02(0.80,1.30)$ & $1.02(0.80,1.28)$ \\
\hline $\mathrm{CD}^{+}$cell count, per 100 cells/ $/ \mathrm{L}$ increase & $0.92(0.86,0.99)$ & $0.98(0.91,1.06)$ & $0.97(0.90,1.05)$ \\
\hline HIV viral load, per $\log _{10}$ copies $/ \mathrm{mL}$ increase & $1.18(1.01,1.38)$ & $1.20(1.01,1.43)$ & $1.20(1.01,1.42)$ \\
\hline Year of CART initiation, per calendar year increase & $0.99(0.94,1.05)$ & $1.07(0.99,1.15)$ & $1.07(0.99,1.15)$ \\
\hline Tenofovir use, per cumulative year of use & $1.17(1.07,1.29)$ & $1.11(0.99,1.24)$ & $1.12(1.00,1.25)$ \\
\hline Atazanavir use, per cumulative year of use & $1.16(1.06,1.28)$ & $1.09(0.98,1.21)$ & $1.10(0.99,1.23)$ \\
\hline Lopinavir use, per cumulative year of use & $1.12(1.03,1.22)$ & $1.12(1.02,1.22)$ & $1.12(1.02,1.23)$ \\
\hline Liver fibrosis (APRI $\geq 1.5$ ) & $1.59(1.08,2.34)$ & $1.50(0.98,2.30)$ & $1.50(0.98,2.30)$ \\
\hline Hypertension & $1.69(0.96,2.99)$ & $\mathrm{N} / \mathrm{A}$ & $1.70(0.91,3.17)$ \\
\hline Diabetes & $3.42(2.29,5.10)$ & N/A & $1.47(0.96,2.26)$ \\
\hline
\end{tabular}

APRI aspartate aminotransferase to platelet ratio index, CART combination antiretroviral therapy, Cl confidence interval, eGFR estimated glomerular filtration rate, $H R$ hazard ratio, N/A not available

${ }^{a}$ Multiple imputation used for missing data

${ }^{\mathrm{b}}$ Age and baseline eGFR were modeled with a linear spline

c Hypertension and diabetes excluded from the model

${ }^{d}$ Hypertension and diabetes included in the model 
There are several possible mechanisms by which HCV increases the risk of CKD. Declines in renal function could be brought about HCV-induced glomerular diseases, namely membranoproliferative glomerulonephritis, which is driven by deposition of mixed immune complexes in the glomerular units of the kidney [8]. Indeed, a biopsy study of 249 HIV patients with CKD found that co-infected patients were twice as likely to have histopathologic evidence of immunecomplex glomerulonephritides, compared to HIV mono-infected patients [50]. Alternatively, HCV coinfection may be associated with CKD by increasing the prevalence of traditional CKD risk factors. In HIV-infected populations, co-infection has been associated with insulin resistance [51] and increases in carotid intima-media thickness and atherosclerosis [52], early markers for diabetes and cardiovascular disease, respectively. Lastly, as with HIV, there is evidence that persistent $\mathrm{HCV}$ replication can result in systematic inflammation and immune activation leading to endothelial dysfunction, which is prevalent in patients with severe renal failure [53, 54].

As with previous research, we were unable to account for the possible role that current IDU practices may have on CKD. Active IDU is prevalent among co-infected individuals and has been associated with increases in serum creatinine concentration [55]. Previous research in coinfected populations have demonstrated that frequent use of injection cocaine, a known nephrotoxic stimulant, may explain part of the association between chronic HCV and CKD observed in previous studies [56]. In our analysis, IDU as a HIV risk factor was strongly collinear with HCV co-infection and therefore not included in multivariable analyses. Furthermore, past IDU is often a poor proxy and imperfect measure for current IDU behaviour. In the Canadian Co-Infection Cohort, for example, $81 \%$ of participants have an IDU risk factor, but only 34\% remained active users [25]. We found no evidence, however, that the role of HCV co-infection differed between those with and without a past IDU risk factor, as has been suggested for HIV treatment outcomes, such as virologic suppression, $\mathrm{CD}^{+}{ }^{+}$recovery and all-cause mortality [31]. Co-infected patients may also experience higher levels of additional CKD risk factors, such as NSAID use, smoking, alcohol abuse, and food insecurity, compared to HIV monoinfected patients. These variables were not available in CANOC and thus we cannot ascertain how much they contribute to our observed association.

If $\mathrm{HCV}$ co-infection is an important driver of CKD in HIV-infected patients in the modern cART era, then CKD is an extrahepatic complication that can potentially be impacted with wider uptake of HCV treatment with new direct acting antivirals. Indeed, a recent study found that HCV-HIV co-infected responders who were successfully treated with pegylated-interferon and ribavirin had a $60 \%$ reduction in the risk of renal events, compared to individuals who failed treatment [57]. These findings provide further evidence of a direct effect of ongoing $\mathrm{HCV}$ viral replication on CKD etiology in HIV-infected populations.

Our study has several limitations. First, we excluded a large proportion of patients who did not have a baseline serum creatinine measurement. These patients, who were more likely to be female, white and be HCV co-infected, were excluded because we could not determine if they had prevalent CKD at cART initiation. In a sensitivity analyses where included patients were weighted by their inverse-probability of being selected into the analysis, we found little evidence of selection bias as a result of our exclusion criteria. Second, the use of a single HCV antibody serology, without RNA testing confirmation, as part of the HCV exposure definition may result in misclassification, as approximately $20 \%$ of individuals will spontaneously clear their HCV infection within a year of exposure and will no longer be viremic. This misclassification is likely non-differential with respect to time to incident CKD and biases our findings towards the null. Third, CANOC patients exposed to $\mathrm{HCV}$ may have subsequently initiated treatment and could have developed a sustained virologic response. We expect this misclassification of person-time to be small as both the uptake of HCV treatment and SVR rates among HIV coinfected patients in the pre direct-acting antiviral era are low [25]. Fourth, given the asymptomatic nature of chronic $\mathrm{HCV}$ infection, we assumed HCV infection was present at baseline and subjects did not seroconvert after starting cART even if their first positive test or diagnosis occurred after treatment initiation. This assumption may not be valid if subjects engaged in high-risk behavior after starting CART, however previous studies have shown that HCV infection is often acquired prior to starting treatment and seroconversion is relatively rare when on stable cART $[25,58]$. Fifth, we had no information regarding quantitative $\mathrm{HCV}$ viral load to further evaluate the association between viral replication and CKD, as has been suggested earlier [44]. This has limited our ability to assess the plausibility of $\mathrm{HCV}$ as an etiologic CKD risk factor. Finally, we did not have data on proteinuria measurements preventing the use of more rigorous CKD staging definitions [59].

\section{Conclusions}

The risk of CKD was more than two-fold greater in HCV co-infected compared to HIV mono-infected patients. Whether this risk is a solely a direct effect of $\mathrm{HCV}$ viral replication or is in part related to other associated risk factors, such as IDU, remains to be determined. Regardless, HCV-HIV co-infected individuals should be regularly 
screened for CKD to identify those who may require modifications to potentially nephrotoxic HIV treatments and those who may benefit from interventions to reduce further decline in kidney function such as $\mathrm{HCV}$ treatment with new direct-acting antiviral therapy.

\section{Additional file}

\section{Additional file 1: Supplemental content (Tables S1 to S4).}

(PDF $187 \mathrm{~kb}$ )

\begin{abstract}
Abbreviations
AIDS: Acquired immune deficiency syndrome; APRI: Aspartate aminotransferase to platelet ratio index; CANOC: Canadian Observational Cohort; CART: Combination antiretroviral therapy; Cl: Confidence interval; CKD: Chronic kidney disease; eGFR: Estimated glomerular filtration rate; ESRD: End-stage renal disease; HCV: Hepatitis C virus; HIV: Human immunodeficiency virus; HIVAN: HIV-associated nephropathy; HR: Hazard ratio; IDU: Injection drug use; IQR: Interquartile range; MI: Multiple imputation; NSAID: Nonsteroidal anti-inflammatory drug; PH: Proportional hazards; PYFU: Person-years of follow-up; SCr: Serum creatinine
\end{abstract}

\section{Acknowledgements}

We would like to thank all of the participants for allowing their information to be a part of the CANOC collaboration and Karyn Gabler and Chantal Burelle for their help with the submission process. The data was presented in part previously as a poster presentation at the 25th Annual Canadian Conference on HIV/AIDS Research in Winnipeg, Manitoba, on May 13th, 2016.

\section{Funding}

CANOC is funded by the Canadian Institutes of Health Research (CIHR) through a Centres Grant (Centres for HIV/AIDS Population Health and Health Services Research [CIHR \#02684]); two Operating Grants (HIV/AIDS Priority Announcement [CIHR \#134047]; a Population and Public Health Grant [CIHR \#136882]); a Foundation Grant (Expansion of Antiretroviral Therapy and its Impact on Vulnerable Populations in Canada and Global Settings [CIHR \#143342]); and in collaboration with the CIHR Canadian HIV Trials Network [CTN \#242]. CR was supported by doctoral research award from the Canadian Institutes of Health Research. JR is supported by an Ontario HIV Treatment Network Chair in Biostatistics. EEMM is supported by a ChercheurBoursier Junior 2 Career Award from the Fonds de recherche en santé du Québec (FRQ-S). MBK is supported by a Chercheur National Career Award from the FRQ-S. The funders had no role in the design of the study, data collection, analysis, interpretation of data and the decision to publish the manuscript.

\section{Availability of data and materials}

There are data sharing agreements in place that prohibit the authors from making the data set publicly available. Readers may contact Dr. Robert Hogg for further clarification.

\section{Authors' contributions}

All authors contributed to this study, as required by the International Committee of Medical Journal Editors. CR, EEMM and MBK conceived of and designed the study. JC prepared the analytical dataset. CR performed all statistical analyses. CR and MBK drafted the initial manuscript, and all authors revised the document critically and gave final approval prior to completion. All authors take responsibility for the accuracy and integrity of this work.

\section{Authors' information}

The CANOC Collaborative Research Centre includes: CANOC Principal Investigator: Robert Hogg (British Columbia Centre for Excellence in HIV/AIDS, Simon Fraser University), site Principal Investigators: Ann N. Burchell (Ontario HIV Treatment Network, University of Toronto, OHTN Cohort Study [OCS]), Curtis Cooper (University of Ottawa, OCS), Deborah Kelly (Memorial University of Newfoundland), Marina Klein (Montreal Chest Institute Immunodeficiency Service Cohort, McGill University), Mona Loutfy
(University of Toronto, Maple Leaf Medical Clinic, OCS), Nima Machouf (Clinique Medicale l'Actuel, Université de Montréal), Julio Montaner (British Columbia Centre for Excellence in HIV/AIDS, University of British Columbia), Janet Raboud (University of Toronto, University Health Network, OCS), Chris Tsoukas (McGill University), Stephen Sanche (University of Saskatchewan), Alexander Wong (University of Saskatchewan) Co-Principal Investigators: Tony Antoniou (St. Michael's Hospital, University of Toronto, Institute for Clinical Evaluative Sciences), Ahmed Bayoumi (St. Michael's Hospital, University of Toronto), Mark Hull (British Columbia Centre for Excellence in HIV/AIDS), Bohdan Nosyk (British Columbia Centre for Excellence in HIV/AIDS, Simon Fraser University) Co-Investigators: Angela Cescon (Northern Ontario School of Medicine), Michelle Cotterchio (Cancer Care Ontario, University of Toronto), Charlie Goldsmith (Simon Fraser University), Silvia Guillemi (British Columbia Centre for Excellence in HIV/AIDS, University of British Columbia), P. Richard Harrigan (British Columbia Centre for Excellence in HIV/ AIDS, University of British Columbia), Marianne Harris (St. Paul's Hospital), Sean Hosein (CATIE), Sharon Johnston (Bruyère Research Institute, University of Ottawa), Claire Kendall (Bruyère Research Institute, University of Ottawa), Clare Liddy (Bruyère Research Institute, University of Ottawa), Viviane Lima (British Columbia Centre for Excellence in HIV/AIDS, University of British Columbia), David Marsh (Northern Ontario School of Medicine), David Moore (British Columbia Centre for Excellence in HIV/ AIDS, University of British Columbia), Alexis Palmer (British Columbia Centre for Excellence in HIV/AIDS, Simon Fraser University), Sophie Patterson (British Columbia Centre for Excellence in HIV/AIDS, Simon Fraser University), Peter Phillips (British Columbia Centre for Excellence in HIV/AIDS, University of British Columbia), Anita Rachlis (University of Toronto, OCS), Sean B. Rourke (University of Toronto, OCS), Hasina Samji (British Columbia Centre for Excellence in HIV/AIDS), Marek Smieja (McMaster University), Benoit Trottier (Clinique Medicale I'Actuel, Université de Montréal), Mark Wainberg (McGill University, Lady Davis Institute for Medical Research), Sharon Walmsley (University Health Network, University of Toronto) Collaborators: Chris Archibald (Public Health Agency of Canada Centre for Communicable Diseases and Infection Control), Ken Clement (Canadian Aboriginal AIDS Network), Fred Crouzat (Maple Leaf Medical Clinic), Monique Doolittle-Romas (Canadian AIDS Society), Laurie Edmiston (Canadian Treatment Action Council), Sandra Gardner (OHTN, University of Toronto, OCS), Brian Huskins (Canadian Treatment Action Council), Jerry Lawless (University of Waterloo), Douglas Lee (University Health Network, University of Toronto, ICES), Renee Masching (Canadian Aboriginal AIDS Network), Stephen Tattle (Canadian Working Group on HIV \& Rehabilitation), Alireza Zahirieh (Sunnybrook Health Sciences Centre) Analysts and Staff: Claire Allen (Regina General Hospital), Stryker Calvez (SHARE), Guillaume Colley (British Columbia Centre for Excellence in HIV/AIDS), Jason Chia (British Columbia Centre for Excellence in HIV/AIDS), Daniel Corsi (The Ottawa Hospital Immunodeficiency Clinic, Ottawa Hospital Research Institute), Louise Gilbert (Immune Deficiency Treatment Centre), Nada Gataric (British Columbia Centre for Excellence in HIV/AIDS), Alia Leslie (British Columbia Centre for Excellence in HIV/ AIDS), Lucia Light (OHTN), David Mackie (The Ottawa Hospital), Costas Pexos (McGill University), Susan Shurgold (British Columbia Centre for Excellence in HIV/AIDS), Leah Szadkowski (University Health Network), Chrissi Galanakis (Clinique Médicale L'Actuel), Ina Sandler (Maple Leaf Medical Clinic), Benita Yip (British Columbia Centre for Excellence in HIV/AIDS), Jaime Younger (University Health Network), and Julia Zhu (British Columbia Centre for Excellence in HIV/AIDS).

\section{Competing interests}

$J R$ is a co-investigator on two projects outside the submitted work with in-kind support from Gilead Sciences and Merck. SW has sat on advisory boards and has spoken at events for ViiV Healthcare, Gilead Sciences, Merck and Janssen. CC has received research grants, sat on advisory boards and has spoken at events for Gilead Sciences, Merck and AbbVie. $\mathrm{MH}$ has participated in advisory boards or speaking engagements for Abbvie, BMS, Gilead, Janssen, and Merck. All honoraria have been paid to his institution. MBK has received research grants for investigatorinitiated trials from Merck and ViiV Healthcare; consulting fees from ViiV Healthcare, Bristol-Meyers Squibb, Merck, Gilead and AbbVie. CR, $T A, A B, J C, R S H$, and EEMM have no conflicts to declare.

Consent for publications

Not applicable. 


\section{Ethics approval and consent to participate}

The human subjects activities of CANOC were approved by the Simon Fraser University Research Ethics Board, the University of British Columbia Research Ethics Board and the following local institutional review boards of the participating cohorts: Providence Health Care Research Institute Office of Research Services, The Ottawa Hospital Research Ethics Board, University Health Network (UHN) Research Ethics Board, Véritas Institutional Review Board (IRB), Biomedical C (BMC) Research Ethics Board of the McGill University Heath Centre (MUHC), University of Toronto HIV Research Ethics Board (HIV REB), and Women's College Hospital Research Ethics Board. Local cohort studies have obtained written consent except for the following: HAART Observational Medical Evaluation and Research (IRB approves the retrospective use of anonymous administrative data without requiring consent; an information sheet for participants is provided in lieu of a consent form); Ottawa Hospital Cohort (IRB approves the anonymous use of data retrospectively abstracted from clinical care databases without requiring consent); UHN (REB approves the anonymous use of data retrospectively abstracted from clinical care databases without requiring consent); MUHC (IRB approves the anonymous use of data retrospectively abstracted from clinical care databases without requiring consent; patients sign a general waiver on opening a medical chart at the hospital but no specific study related consent); Maple Leaf Medical Clinic (REB has approved the anonymous use of data retrospectively abstracted from clinical care databases without requiring consent); and Effective Anti-Retroviral Therapy cohort (REB approves the anonymous use of data retrospectively abstracted from clinical care databases without requiring consent; patients sign a general waiver on opening a medical chart at the hospital but no specific study related consent).

\section{Author details}

'Research Institute of the McGill University Health Centre, Montréal, Canada. ${ }^{2}$ Dalla Lana School of Public Health, University of Toronto, Toronto, Canada. ${ }^{3}$ Toronto General Hospital Research Institute, University Health Network, Toronto, Canada. ${ }^{4}$ The Ottawa Hospital, General Campus, Ottawa, Canada. ${ }^{5}$ St. Michael's Hospital, University of Toronto, Toronto, Canada. ${ }^{6} \mathrm{BC}$ Centre for Excellence in HIV/AIDS, Vancouver, Canada. ${ }^{7}$ Faculty of Medicine, University of British Columbia, Vancouver, Canada. ${ }^{8}$ Faculty of Health Sciences, Simon Fraser University, Vancouver, Canada. ${ }^{9}$ Department of Epidemiology, Biostatistics and Occupational Health, McGill University, Montréal, Canada.

${ }^{10}$ Division of Infectious Diseases and Chronic Viral Illness Service, McGill University Health Centre, 1001 Decarie Boulevard, D02.4110, Montréal H4A 3J1, Canada.

\section{Received: 13 December 2016 Accepted: 28 March 2017} Published online: 04 April 2017

\section{References}

1. Lima VD, Lourenco L, Yip B, Hogg RS, Phillips P, Montaner JS. AIDS incidence and AIDS-related mortality in British Columbia, Canada, between 1981 and 2013: a retrospective study. Lancet HIV. 2015;2: e92-7.

2. Patterson S, Cescon A, Samji H, Chan K, Zhang W, Raboud J, et al. Life expectancy of HIV-positive individuals on combination antiretroviral therapy in Canada. BMC Infect Dis. 2015;15:274.

3. Nsanzimana S, Remera E, Kanters S, Chan K, Forrest JI, Ford N, et al. Life expectancy among HIV-positive patients in Rwanda: a retrospective observational cohort study. Lancet Glob Health 2015:3:e169-77.

4. Deeks SG, Phillips AN. HIV infection, antiretroviral treatment, ageing, and non-AIDS related morbidity. BMJ. 2009;338:a3172.

5. Peters L, Klein MB. Epidemiology of hepatitis $C$ virus in HIV-infected patients. Curr Opin HIV AIDS. 2015;10:297-302.

6. Lee MH, Yang HI, Lu SN, Jen CL, You SL, Wang LY, et al. Chronic hepatitis C virus infection increases mortality from hepatic and extrahepatic diseases: a community-based long-term prospective study. J Infect Dis. 2012;206:469-77.

7. Negro F, Forton D, Craxi A, Sulkowski MS, Feld JJ, Manns MP. Extrahepatic morbidity and mortality of chronic hepatitis C. Gastroenterology. 2015;149:1345-60.

8. Soriano V, Berenguer J. Extrahepatic comorbidities associated with hepatitis C virus in HIV-infected patients. Curr Opin HIV AIDS. 2015;10:309-15.
9. Tong X, Spradling PR. Increase in nonhepatic diagnoses among persons with hepatitis C hospitalized for any cause, United States, 2004-2011. J Viral Hepat. 2015;22:906-13.

10. Crowell TA, Berry SA, Fleishman JA, LaRue RW, Korthuis PT, Nijhawan AE, et al. Impact of hepatitis coinfection on healthcare utilization among persons living with HIV. J Acquir Immune Defic Syndr. 2015;68:425-31.

11. Lucas GM, Ross MJ, Stock PG, Shlipak MG, Wyatt CM, Gupta SK, et al. Clinical practice guideline for the management of chronic kidney disease in patients infected with HIV: 2014 update by the HIV Medicine Association of the Infectious Diseases Society of America. Clin Infect Dis. 2014;59:e96-138.

12. Choi Al, Li Y, Deeks SG, Grunfeld C, Volberding PA, Shlipak MG. Association between kidney function and albuminuria with cardiovascular events in HIV-infected persons. Circulation. 2010;121:651-8.

13. Mocroft A, Ryom L, Begovac J, Monforte A, Vassilenko A, Gatell J, et al. Deteriorating renal function and clinical outcomes in HIV-positive persons. AIDS. 2014;28:727-37.

14. Ryom L, Lundgren JD, Ross M, Kirk O, Law M, Morlat P, et al. Renal impairment and cardiovascular disease in HIV-positive individuals: the D:A:D study. J Infect Dis. 2016;214:1212-20.

15. Roling J, Schmid H, Fischereder M, Draenert R, Goebel FD. HIV-associated renal diseases and highly active antiretroviral therapy-induced nephropathy. Clin Infect Dis. 2006:42:1488-95.

16. Mocroft A, Kirk O, Reiss P, De Wit S, Sedlacek D, Beniowski M, et al. Estimated glomerular filtration rate, chronic kidney disease and antiretroviral drug use in HIV-positive patients. AIDS. 2010;24:1667-78,

17. Ryom L, Mocroft A, Lundgren JD. Antiretroviral therapy, immune suppression and renal impairment in HIV-positive persons. Curr Opin HIV AIDS. 2014;9:41-7.

18. Johnson RJ, Gretch DR, Yamabe H, Hart J, Bacchi CE, Hartwell P, et al. Membranoproliferative glomerulonephritis associated with hepatitis $C$ virus infection. N Engl J Med. 1993:328:465-70.

19. Pipili C, llonidis G, Cholongitas E. Hepatitis C virus and kidney: a strong association with different clinical aspects. Liver Int. 2011;31:1071-80.

20. Miyajima I, Kawaguchi T, Fukami A, Nagao Y, Adachi H, Sasaki S, et al. Chronic HCV infection was associated with severe insulin resistance and mild atherosclerosis: a population-based study in an HCV hyperendemic area. J Gastroenterol. 2013:48:93-100.

21. Wyatt CM, Malvestutto C, Coca SG, Klotman PE, Parikh CR. The impact of hepatitis $C$ virus coinfection on HIV-related kidney disease: a systematic review and meta-analysis. AIDS. 2008;22:1799-807.

22. Palmer AK, Klein MB, Raboud J, Cooper C, Hosein S, Loutfy M, et al. Cohor profile: the Canadian Observational Cohort collaboration. Int J Epidemiol. 2011;40:25-32.

23. Levey AS, Stevens LA, Schmid CH, Zhang YL, Castro 3rd AF, Feldman HI, et al. A new equation to estimate glomerular filtration rate. Ann Intern Med. 2009:150:604-12.

24. Inker LA, Wyatt C, Creamer R, Hellinger J, Hotta M, Leppo M, et al. Performance of creatinine and cystatin C GFR estimating equations in an HIV-positive population on antiretrovirals. J Acquir Immune Defic Syndr. 2012;61:302-9.

25. Klein MB, Rollet KC, Saeed S, Cox J, Potter M, Cohen J, et al. HIV and hepatitis $C$ virus coinfection in Canada: challenges and opportunities for reducing preventable morbidity and mortality. HIV Med. 2013;14:10-20.

26. Mocroft A, Reiss P, Gasiorowski J, Ledergerber B, Kowalska J, Chiesi A, et al. Serious fatal and nonfatal non-AIDS-defining illnesses in Europe. J Acquir mmune Defic Syndr. 2010;55:262-70.

27. Wai CT, Greenson JK, Fontana RJ, Kalbfleisch JD, Marrero JA, Conjeevaram $\mathrm{HS}$, et al. A simple noninvasive index can predict both significant fibrosis and cirrhosis in patients with chronic hepatitis C. Hepatology. 2003:38:518-26.

28. 1993 revised classification system for HIV infection and expanded surveillance case definition for AIDS among adolescents and adults. MMWR Recomm Rep. 1992;41(RR-17):1-19.

29. Kalbfleisch JD, Prentice RL. The statistical analysis of failure time data. New York: Wiley; 1980

30. Greenland S. Dose-response and trend analysis in epidemiology: alternatives to categorical analysis. Epidemiology. 1995;6:356-65.

31. Cescon A, Chan K, Raboud JM, Burchell AN, Forrest JI, Klein MB, et al. Significant differences in clinical outcomes between HIV-hepatitis C virus 
coinfected individuals with and without injection drug use history. AIDS 2014;28:121-7.

32. White IR, Royston P, Wood AM. Multiple imputation using chained equations: issues and guidance for practice. Stat Med. 2011;30:377-99.

33. White IR, Royston P. Imputing missing covariate values for the Cox model. Stat Med. 2009:28:1982-98.

34. Seaman SR, White IR. Review of inverse probability weighting for dealing with missing data. Stat Methods Med Res. 2013:22:278-95.

35. Gillis J, Cooper C, Burchell AN, Gardner S, Manno M, Mazzulli T, et al. Timedependent bias in hepatitis C classification. Epidemiology. 2015;26:e24-6.

36. Carpenter JR, Kenward MG. Multiple imputation and its application. West Sussex: Wiley; 2013.

37. Gupta SK, Eustace JA, Winston JA, Boydstun II, Ahuja TS, Rodriguez RA, et al. Guidelines for the management of chronic kidney disease in HIV-infected patients: recommendations of the HIV Medicine Association of the Infectious Diseases Society of America. Clin Infect Dis. 2005;40:1559-85.

38. Pozniak A, Arribas JR, Gathe J, Gupta SK, Post FA, Bloch M, et al. Switching to tenofovir alafenamide, coformulated with elvitegravir, cobicistat, and emtricitabine, in HIV-infected patients with renal impairment: 48-week results from a single-arm, multicenter, open-label phase 3 study. J Acquir Immune Defic Syndr. 2016;71:530-7.

39. Tsui J, Vittinghoff E, Anastos K, Augenbraun M, Young M, Nowicki M, et al. Hepatitis $C$ seropositivity and kidney function decline among women with HIV: data from the Women's Interagency HIV Study. Am J Kidney Dis. 2009;54:43-50

40. Peters $L$, Grint $D$, Lundgren JD, Rockstroh JK, Soriano V, Reiss $P$, et al. Hepatitis $C$ virus viremia increases the incidence of chronic kidney disease in HIV-infected patients. AIDS. 2012;26:1917-26.

41. Wyatt CM, Winston JA, Malvestutto CD, Fishbein DA, Barash I, Cohen AJ, et al. Chronic kidney disease in HIV infection: an urban epidemic. AIDS. 2007;21:2101-3.

42. Achhra AC, Mocroft A, Ross MJ, Ryom L, Lucas GM, Furrer H, et al. Kidney disease in antiretroviral-naive HIV-positive adults with high CD4 counts: prevalence and predictors of kidney disease at enrolment in the INSIGHT Strategic Timing of AntiRetroviral Treatment (START) trial. HIV Med. 2015; 16(Suppl 1):55-63.

43. Morlat P, Vivot A, Vandenhende MA, Dauchy FA, Asselineau J, Deti E, et al. Role of traditional risk factors and antiretroviral drugs in the incidence of chronic kidney disease, ANRS CO3 Aquitaine cohort, France, 2004-2012. PLoS One. 2013;8:e66223.

44. Mocroft A, Neuhaus J, Peters L, Ryom L, Bickel M, Grint D, et al. Hepatitis B and C co-infection are independent predictors of progressive kidney disease in HIVpositive, antiretroviral-treated adults. PLoS One. 2012;7:e40245.

45. Mocroft A, Lundgren JD, Ross M, Law M, Reiss P, Kirk O, et al. Development and validation of a risk score for chronic kidney disease in HIV infection using prospective cohort data from the D:A:D study. PLoS Med. 2015;12:e1001809.

46. Mocroft A, Lundgren JD, Ross M, Fux CA, Reiss P, Moranne O, et al. Cumulative and current exposure to potentially nephrotoxic antiretrovirals and development of chronic kidney disease in HIV-positive individuals with a normal baseline estimated glomerular filtration rate: a prospective international cohort study. Lancet HIV. 2016;3:e23-32.

47. Lucas GM, Lau B, Atta MG, Fine DM, Keruly J, Moore RD. Chronic kidney disease incidence, and progression to end-stage renal disease, in HIVinfected individuals: a tale of two races. J Infect Dis. 2008;197:1548-57.

48. Abraham AG, Althoff KN, Jing Y, Estrella MM, Kitahata MM, Wester CW, et al. End-stage renal disease among HIV-infected adults in North America. Clin Infect Dis. 2015;60:941-9.

49. Lucas GM, Eustace JA, Sozio S, Mentari EK, Appiah KA, Moore RD. Highly active antiretroviral therapy and the incidence of HIV-1-associated nephropathy: a 12-year cohort study. AIDS. 2004;18:541-6.

50. George E, Nadkarni GN, Estrella MM, Lucas GM, Sperati CJ, Atta MG, et al. The impact of hepatitis $C$ coinfection on kidney disease related to human immunodeficiency virus (HIV): a biopsy study. Medicine. 2011;90:289-95.

51. Hull MW, Rollet K, Moodie EE, Walmsley S, Cox J, Potter M, et al. Insulin resistance is associated with progression to hepatic fibrosis in a cohort of HIV/hepatitis C virus-coinfected patients. AIDS. 2012;26:1789-94.

52. McKibben RA, Haberlen SA, Post WS, Brown TT, Budoff M, Witt MD, et al. A cross-sectional study of the association between chronic hepatitis $C$ virus infection and subclinical coronary atherosclerosis among participants in the Multicenter AIDS Cohort Study. J Infect Dis. 2016;213:257-65.

53. de Castro IF, Micheloud D, Berenguer J, Guzman-Fulgencio M, Catalan P, Miralles $P$, et al. Hepatitis $C$ virus infection is associated with endothelial dysfunction in HIV/hepatitis C virus coinfected patients. AIDS. 2010;24:2059-67.

54. Ochodnicky P, Vettoretti S, Henning RH, Buikema H, Van Dokkum RP, de Zeeuw D. Endothelial dysfunction in chronic kidney disease: determinant of susceptibility to end-organ damage and therapeutic response. J Nephrol. 2006;19:246-58.

55. Garg S, Hoenig M, Edwards EM, Bliss C, Heeren T, Tumilty S, et al. Incidence and predictors of acute kidney injury in an urban cohort of subjects with HIV and hepatitis C virus coinfection. AIDS Patient Care STDs. 2011;25:135-41.

56. Rossi C, Cox J, Cooper C, Martel-Laferriere V, Walmsley S, Gill J, et al. Frequent injection cocaine use increases the risk of renal impairment among hepatitis C and HIV co-infected patients. AIDS. 2016;30:1403-11.

57. Berenguer J, Von Wichmann MA, Lopez-Aldeguer J, Galindo MJ, Mallolas J, Crespo M, et al. Eradication of HCV and extrahepatic comorbidities in HIV/HCV coinfection. Conference on Retroviruses and Opportunistic Infections 2016. Abstract \#611; Boston.

58. Burchell AN, Gardner SL, Mazzulli T, Manno M, Raboud J, Allen VG, et al. Hepatitis C virus seroconversion among HIV-positive men who have sex with men with no history of injection drug use: results from a clinical HIV cohort. Can J Infect Dis Med Microbiol. 2015;26:17-22.

59. Levey AS, Coresh J. Chronic kidney disease. Lancet. 2012;379:165-80.

\section{Submit your next manuscript to BioMed Central and we will help you at every step:}

- We accept pre-submission inquiries

- Our selector tool helps you to find the most relevant journal

- We provide round the clock customer support

- Convenient online submission

- Thorough peer review

- Inclusion in PubMed and all major indexing services

- Maximum visibility for your research

Submit your manuscript at www.biomedcentral.com/submit
C) Biomed Central 